\title{
Modulatory effects of the amygdala on oestrogen- induced LH secretion in ovariectomized rats
}

\author{
M. N. Perkins and S. A. Whitehead \\ Department of Physiology, St. George's Hospital Medical School, Cranmer Terrace, Tooting, \\ London SWI7 ORE, U.K.
}

\begin{abstract}
Summary. An increase in LH secretion was induced in ovariectomized oestradiol benzoate-primed rats $5 \mathrm{~h}$ after a second injection of oestradiol benzoate. Lesions stereotaxically placed in the cortical and basomedial amygdala of steroid-primed rats abolished this rise. The results provide evidence for a facilitatory action of the amygdala upon LH release and an involvement of this region of the limbic system in oestrogen-feedback mechanisms.
\end{abstract}

\section{Introduction}

The role of the amygdala in sexual maturation and the control of ovulation is controversial (Ellendorf, 1976), although there is evidence that steroid feedback mechanisms are located in this area of the brain (Pfaff \& Keiner, 1973; Kawakami, Kimura \& Konda, 1976) and that it is involved in the secretion of gonadotrophins. Velasco \& Taleisnik (1969) reported that electrochemical stimulation of the corticomedial and basolateral amygdala produced ovulation in persistent oestrous rats. Plasma LH levels rise after amygdaloid stimulation (Velasco \& Taleisnik, 1969; Kawakami, Terasawa, Kimura \& Wakabayashi, 1973) and transections of the stria terminalis prevent ovulation in the cyclic female rat (Velasco \& Taleisnik, 1971). In contrast, other workers have presented evidence favouring an inhibitory action of the amygdala on gonadotrophin secretion (Eleftheriou \& Zolovick, 1967; Ellendorff, Colombo, Blake, Whitmoyer \& Sawyer, 1973).

A convenient model for investigating the involvement of specific brain regions in gonadotrophin secretion is the ovariectomized rat that has been primed with oestrogen. If a second oestrogen injection is given $72 \mathrm{~h}$ later, when circulating gonadotrophin levels are markedly reduced, there is an increased secretion of $\mathrm{LH}$ within $5 \mathrm{~h}$ which resembles the preovulatory LH surge in intact cyclic rats (Brown-Grant, 1974; Caligaris, Astrada \& Taleisnik, 1971). In the present experiments, we have used this model to study the effects of lesions of the amygdala.

\section{Materials and Methods}

The rats used were adult virgin Porton-Wistar rats weighing between 190 and $310 \mathrm{~g}$. They were housed in an isolated room at a constant temperature of $21^{\circ} \mathrm{C}$ with artifical lighting provided between 06:00 and 21:00 h. They were bilaterally ovariectomized and, at least 3 weeks later, received $20 \mu \mathrm{g}$ oestradiol benzoate (Sigma, London) intramuscularly (i.m.) dissolved in arachis oil. The second injection (i.m.) of $20 \mu \mathrm{g}$ oestradiol benzoate was given $72 \mathrm{~h}$ later between 11:30 and 12:30 h. Blood samples, which were obtained by cardiac puncture under light ether anaesthesia, were taken just before each injection and $5 \mathrm{~h}$ after the second injection.

The animals were allocated to 4 groups. The controls in Group 1 received both the oestrogen injections, while the controls in Group 2 received the first oestradiol injection but arachis oil only for the second. The rats in Group 3 had bilateral lesions sterotaxically placed in the amygdala 
(co-ordinates AP 4.8, L 4.5-5.0, H 3.5: DeGroot, 1959). Lesions were made immediately after the first blood samples were taken but before the second oestradiol injection. A high-frequency Grass LM4 lesion maker was used, and current was passed through a stainless-steel epoxy resincoated electrode for $20 \mathrm{sec}$ at an intensity of 4-10 mA. The animals in Group 4 had the same treatment as those in Group 3, except that no current was passed through the electrode. After the final blood sample was taken, the rats in Groups 3 and 4 were perfused with $10 \%$ formol saline and the brains were removed and fixed. Serial histological sections of the brain were examined to confirm placement and size of lesions. Any animals with signs of damage to the stria terminalis were excluded from the analysis.

Serum from the blood samples was stored at $-20^{\circ} \mathrm{C}$ and $\mathrm{LH}$ levels were measured by a double-antibody radioimmunoassay using kits supplied by NIAMDD. A standard curve was constructed encompassing the range 0-1000 ng NIAMDD rat-LH-RP $1 / \mathrm{ml}$ serum, from which triplicate samples were interpolated by computer analysis. Inter- and intra-assay coefficients of variation were 18 and $5 \%$ respectively. Statistical significance was determined by the KruskalWallis analysis of variance.

\section{Results}

The results are shown in Table 1. The first injection resulted in a significant fall in serum LH levels which was of a similar magnitude in all 4 groups. At $5 \mathrm{~h}$ after the second injection, LH concentrations were increased in Groups $1(n=10)$ and $4(n=9)$ but unchanged in Groups 2 $(n=5)$ and $3(n=10)$. The difference in the number of samples at each stage is due to rejection from the analysis of any triplicate in which at least 2 of the 3 values were not within $10 \%$ of each other.

Table 1. Mean \pm s.e.m. concentrations of LH in rats (no. in parentheses) ovariectomized (OVX) and treated with oestradiol benzoate $(\mathrm{OB})$ and bilateral lesions of the amygdala

\begin{tabular}{cccc}
\hline & \multicolumn{3}{c}{ LH concentrations (ng/ml) } \\
\cline { 2 - 4 } Group & $3-5$ weeks after OVX & $72 \mathrm{~h}$ after lst injection & 5 h after 2nd injection \\
\hline $\begin{array}{c}1 \\
\text { (OB controls) } \\
2\end{array}$ & $687 \pm 94(13)$ & $* 243 \pm 30(7)$ & $\dagger 696 \pm 61(10)$ \\
(OB and oil controls) & $740 \pm 44(10)$ & $* 381 \pm 48(9)$ & $394 \pm 67(5)$ \\
$\begin{array}{c}3 \\
\text { (OB and lesioned) } \\
4\end{array}$ & $611 \pm 65(14)$ & $* 340 \pm 77(11)$ & $345 \pm 49(10)$ \\
(OB and sham lesioned) & $621 \pm 37(9)$ & $* 301 \pm 57(7)$ & $\dagger 674 \pm 123(9)$ \\
\hline
\end{tabular}

* Significantly different from initial values, $P<0.02$.

$\dagger$ Significantly different from previous value, $P<0.02$.

Histological examination of the brain sections of the lesioned animals showed that the cortical and basomedial nuclei were mostly destroyed, the medial nucleus was also damaged and the basolateral nucleus was largely intact (see Text-fig. 1).

\section{Discussion}

The high levels of serum LH observed 3-5 weeks after ovariectomy and their subsequent reduction $72 \mathrm{~h}$ following oestradiol benzoate administration is compatible with the accepted primary negative feedback effects of oestrogen (Caligaris et al., 1971; Yamaji, Dierschke, Bhattacharya \& Knobil, 1972; Legan \& Karsch, 1974). The expected rise in LH secretion was observed in those animals that had received a second injection of oestradiol $5 \mathrm{~h}$ previously although this surge of $\mathrm{LH}$ was abolished by lesions of the amygdala. 


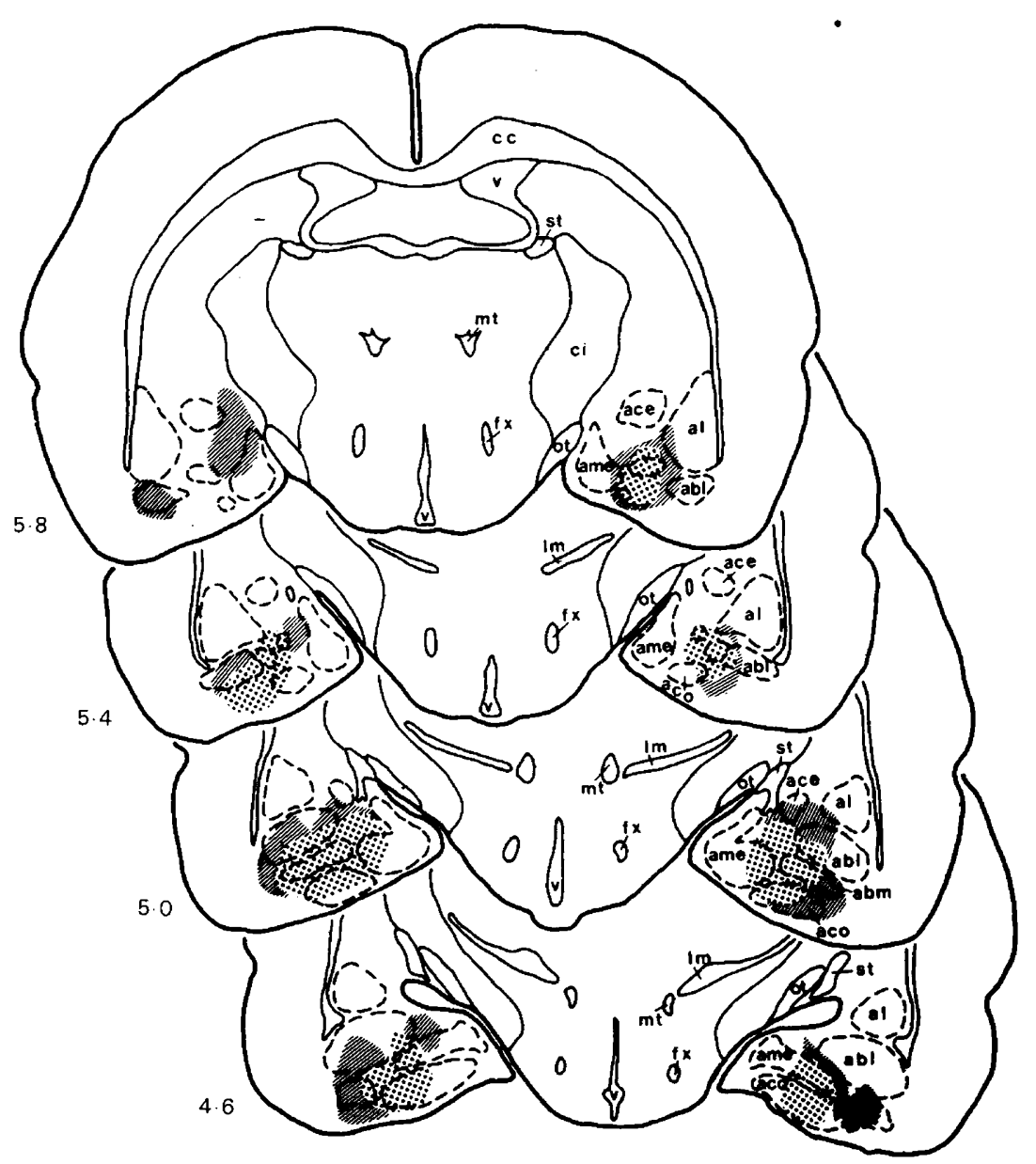

Text-fig. 1. Diagram of coronal sections through the rat forebrain (after DeGroot 1959), showing the extent of the lesions of the amygdala. The light shaded area represents the total limits of all the lesions and the dark shading those ablated areas common to all lesions. abl, basolateral amygdala; abm, basomedial amygdala; ace, central amygdala; aco, cortical amygdala; al, lateral amygdala; ame, medial amygdala; cc, corpus callosum; ci, internal capsule; $\mathrm{fx}$, fornix; Im, lemniscus medialis; mt, tractus mamillo-thalamicus; ot, optic tract; st, stria terminalis; $v$, ventricle. The numbers give the anterior/posterior co-ordinates (AP) according to DeGroot's stereotaxic atlas.

These results suggest that the cortical and/or the basomedial nuclei of the amygdala are facilitatory in this oestradiol-induced increase. They support stimulation studies showing a facilitatory effect of these nuclei on $\mathrm{LH}$ release in the ovariectomized oestradiol-primed rat (Velasco \& Taleisnik, 1969; Beltramino \& Taleisnik, 1978).

Brown-Grant \& Raisman (1972) have studied the role of the amygdala in the steroidinduced LH rise in ovariectomized, oestradiol-primed rats by transecting the stria terminalis. However, they found that LH levels increased in both the control and lesioned rats. The possibility that lesions of this pathway concomitantly damaged adjacent fimbrial fibres of hippocampal origin may account for this discrepancy because stimulation of the hippocampus has been shown to reduce LH release (Velasco \& Taleisnik, 1969).

Inhibitory effects of the amygdala on gonadotrophin secretion have also been described (Elwers \& Critchlow, 1960; Ellendorff et al., 1973; Eleftheriou \& Zolovick, 1967) and it has been 
suggested that the basolateral nucleus suppresses, whereas the corticomedial nuclei facilitates, LH release (Kaada, 1972). However, interpretation of conflicting data should take into account the problems of specificity of lesions and parameters of stimulation, as well as different directions of response between intact, cyclic and ovariectomized rats (Ellendorff, 1976).

We wish to thank Ms N. White for her help with the radioimmunoassay. This work was supported by the MRC. M.N.P. was an S.R.C. Research Student.

\section{References}

Beltramino C. \& Taleisnik, S. (1978) Facilitatory and inhibitory effects of electrochemical stimulation of the amygdala on the release of luteinizing hormone. Brain Res. 144, 95-107.

Brown-Grant, K. (1974) Steroid hormone administration and gonadotrophin secretion in the gonadectomised rat. J. Endocr. 62, 319-332.

Brown-Grant, K. \& Raisman, G. (1972) Reproductive function in the rat following selective destruction of afferent fibres to the hypothalamus from the limbic system. Brain Res. 46, 23-42.

Caligaris, L., Astrada, J.J. \& Taleisnik, S. (1971) Release of luteinizing hormone induced by oestrogen injection into ovariectomised rats. Endocrinology 88, 810-815.

DeGroot, T. (1959) The rat forebrain in stereotaxic coordinates. Trans. R. Neth. Acad. Sci. 52, 1-40.

Eleftheriou, B.E. \& Zolovick, A.J. (1967) Effect of amygdaloid lesions on plasma and pituitary levels of luteinizing hormone. J. Reprod. Fert. 14, 33-37.

Ellendorfi, F. (1976) Evolution of extrahypothalamic control of reproductive physiology. Rev. Physiol. Biochem. Pharmacol. 76, 103-127.

Ellendorf, F., Colombo, J., Blake, C., Whitmoyer, D. \& Sawyer, C.H. (1973) Effects of electrical stimulation of the amygdala on gonadotrophin release and ovulation in the rats. Proc. Soc. exp. Biol. Med. 142, $417-420$.

Elwers, M. \& Critchlow, V. (1960) Precocious ovarian stimulation following hypothalamic and amygdaloid lesions in rats. Am. J. Physiol. 198, 318-385.

Kaada, B.R. (1972) Stimulation and regional ablation of the amygdala complex with reference to functional representation. In Neurobiology of the Amygdala, pp. 205-281. Ed. B. E. Eleftheriou. Plenum Press, New York.

Kawakami, M., Terasawa, E., Kimura, F. \& Wakabayashi, M. (1973) Modulating effect of limbic structures on gonadotrophin release. Neuroendocrinology 12, 1-16.

Kawakami, M., Kimura, F. \& Konda, N. (1976) Role of forebrain structures in the regulation of gonadotrophin secretion. In Neuroendocrine Regulation of Fertility, pp. 110-113. Ed. T. C. Anand-Kumar. Karger, Basel.

Legan, S.J. \& Karsch, F.J. (1974) An analysis of the positive feedback action of estrogen on $\mathrm{LH}$ secretion in the rat. In Recent Studies of Hypothalamic Function, pp. 147-169. Eds M. Lederis \& H. E. Cooper. Karger, Basel.

Pfaff, D. \& Keiner, M. (1973) Atlas of estradiol-concentrating cells in the central nervous system of the female rat. J. Comp. Neurol. 151, 121-158.

Velasco, M.E. \& Taleisnik, S. (1969) Release of gonadotrophins induced by amygdaloid stimulation in the rat. Endocrinology 84, 132-139.

Velasco, M.E. \& Taleisnik, S. (1971) Effects of interception of amygdaloid and hippocampal afferents to the medial hypothalamus on gonadotrophin release. $J$. Endocr. 51, 41-55.

Yamaji, T., Dierschke, D.J. Bhattacharya, A.N. \& Knobil, E. (1972) The negative feedback control by oestradiol and progesterone of LH secretion in OVX of rhesus monkey. Endocrinology 90, 771-777. 